Case Report

\title{
Scedosporiosis in a Combined Kidney and Liver Transplant Recipient: A Case Report of Possible Transmission from a Near-Drowning Donor
}

\author{
Rachael Leek, ${ }^{1}$ Erika Aldag, ${ }^{1}$ Iram Nadeem, ${ }^{1}$ Vikraman Gunabushanam, \\ Ajay Sahajpal, ${ }^{1,2}$ David J. Kramer, ${ }^{2,3}$ and Thomas J. Walsh ${ }^{4}$ \\ ${ }^{1}$ Department of Abdominal Transplant, Aurora St. Luke's Medical Center, Milwaukee, WI, USA \\ ${ }^{2}$ University of Wisconsin School of Medicine and Public Health, Madison, WI 53726, USA \\ ${ }^{3}$ Department of Critical Care, Aurora St. Luke's Medical Center, Milwaukee, WI, USA \\ ${ }^{4}$ Weill Cornell Medicine, Cornell University and New York Presbyterian Hospital, New York, NY, USA
}

Correspondence should be addressed to Erika Aldag; erika.aldag@aurora.org

Received 29 August 2016; Accepted 6 November 2016

Academic Editor: Graeme Forrest

Copyright (C) 2016 Rachael Leek et al. This is an open access article distributed under the Creative Commons Attribution License, which permits unrestricted use, distribution, and reproduction in any medium, provided the original work is properly cited.

Scedosporium spp. are saprobic fungi that cause serious infections in immunocompromised hosts and in near-drowning victims. Solid organ transplant recipients are at increased risk of scedosporiosis as they require aggressive immunosuppression to prevent allograft rejection. We present a case of disseminated Scedosporium apiospermum infection occurring in the recipient of a combined kidney and liver transplantation whose organs were donated by a near-drowning victim and review the literature of scedosporiosis in solid organ transplantation.

\section{Introduction}

Scedosporium is a saprobic fungus that naturally occurs in soil, manure, sewage, and water bodies polluted by environmental contaminants. Cases of infections with Scedosporium spp. are reported worldwide and can range in severity from colonization or local infection to disseminated disease [1-5]. S. apiospermum most commonly infects the lungs as inhalation is often the suspected mode of organism acquisition [6].

The genus Scedosporium includes, but is not limited to, three species that cause life-threatening infections in humans: Scedosporium apiospermum, Scedosporium prolificans (recently renamed Lomentospora prolificans), and Scedosporium aurantiacum [7]. Scedosporium spp. appear as branching septate hyphae when isolated on standard culture media.

Scedosporium spp. have been implicated in neardrowning accidents [8-10]. Indeed Scedosporium spp. are the most common cause of fungal pneumonia, infection of the central nervous system, and disseminated disease following near-drowning events. There are few cases of donor to recipient transmission of infection of Scedosporium spp. and even fewer reports of near-drowning donor transmission of diseases [11, 12]. We report the clinical course and management of disseminated S. apiospermum infection in a combined kidney and liver transplantation case receiving organs from a brain-dead donor who suffered a neardrowning accident; we further review the literature on scedosporiosis in solid organ transplant recipients.

\section{Case Presentation: Donor}

A 41-year-old male fell into a freshwater lake. Emergency responders pulled him from the lake and return of spontaneous circulation was achieved after twenty minutes of resuscitation. Subsequent chest radiographs showed development and worsening of bilateral opacities suspicious for pneumonia. Brain death was declared three days after hospital admission. 


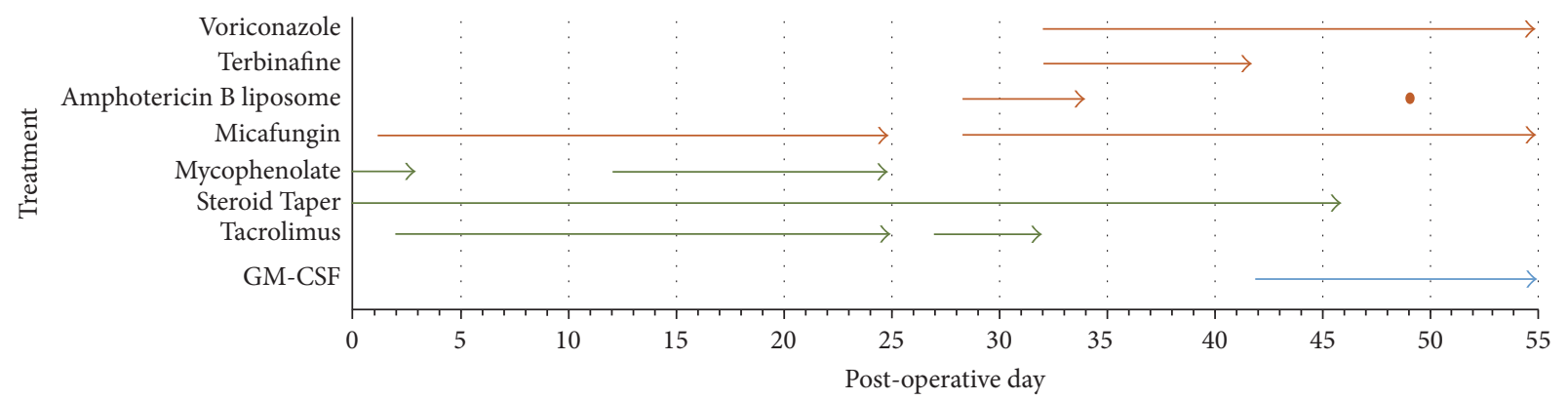

FIgURE 1: Antifungal agents and immunosuppression management.

\section{Case Presentation: Recipient}

A 66-year-old male actively listed for a kidney and liver transplant presented to the surgical intensive care unit with sepsis and an oxacillin-sensitive Staphylococcus aureus bacteremia. He was treated with appropriate antibiotic therapy. He then developed acute tubular necrosis requiring continuous venovenous hemofiltration (CVVH). The patient had a chest Xray showing mild pulmonary congestion and bronchoscopy was not performed as the patient did not show signs of pneumonia. After two weeks within his admission, the patient was treated for Escherichia coli bacteremia with piperacillintazobactam. Repeat blood cultures were negative after two days of therapy.

While the patient was hospitalized, a donor became available. The donor kidney and liver were grossly normal. The patient underwent a combined kidney and liver transplant for chronic kidney failure with associated liver cirrhosis caused by the hepatitis $\mathrm{C}$ virus and alcoholism. The explanted liver was cirrhotic without any malignancy. At the time of transplantation, the patient's Model for End Stage Liver Disease (MELD) score was 40, having been decompensated in the surgical intensive care unit for the previous month. A summary of the patient's immunosuppression and antifungal management after transplant is provided in Figure 1.

The patient was given methylprednisolone $500 \mathrm{mg}$ and mycophenolate mofetil $1,000 \mathrm{mg}$ intraoperatively as induction immunosuppression. Maintenance immunosuppression protocols were followed after transplant. CVVH was performed intraoperatively and was discontinued on postoperative day (POD) 1 when renal graft function improved. The patient's hospital stay was complicated by a contained urine leak from the ureteroureterostomy which was managed nonoperatively with drains and ureteral stents. On POD 8, the patient was transferred out of the intensive care unit and on POD 14, to the inpatient rehab care unit as graft function continued to improve. The hepatic transaminases fluctuated and, on POD 25, he was transferred back to the surgical intensive care unit with peritonitis. As infection was suspected, immunosuppression was restricted to the use of corticosteroids tapered down to prednisone $5 \mathrm{mg}$ daily. The patient was taken back to the operating room on POD 28 for a peritoneal washout. Cultures obtained during the procedure are presented in Tables 1 and 2. Of most concern was the $S$. apiospermum isolated from the perihepatic, perinephric, and biloma fluid. Endoscopic Retrograde Cholangiopancreatography (ERCP) was performed the following day, which did not reveal any extravasation. Discovery of S. apiospermum prompted contact with the Centers for Disease Control and Prevention (CDC), the Disease Transmission Advisory Committee (DTAC) of the United Network for Organ Sharing (UNOS), and the transplant centers treating recipients of allografts from the same donor. Other recipients had no evidence of infection.

On POD 28, due to worsening hemodynamics and peritonitis, another laparotomy and another washout were performed to evacuate an infected hematoma. The entire peritoneal surface was lined with mold. On POD 32, a mold suggestive of Scedosporium spp. grew from surgical cultures. Expert opinion for the management of our patient's suspected S. apiospermum infection was to use voriconazole targeting a trough of $2-4 \mathrm{mcg} / \mathrm{mL}$, which we started on POD 32. Additionally, terbinafine was started for suspected synergy with voriconazole. A sample of the S. apiospermum was sent out for synergy studies which were expected to take a week or more to be conclusive. On POD 41 S. apiospermum was identified. Laboratory results suggested terbinafine was not synergistic with voriconazole. Additionally, terbinafine is distributed rapidly to skin and bone and as such is not distributed well into visceral tissue and accumulation of terbinafine may cause hepatotoxicity. In response, terbinafine was discontinued and granulocyte macrophage colony-stimulating factor (GMCSF) initiated on POD 42. The patient developed neurologic deficits with decreased vision to the right side and blurred vision bilaterally on POD 46. Magnetic resonance imaging (MRI) of the brain, shown in Figure 2, revealed multiple ring-enhancing lesions in the supratentorial compartment consistent with hematogenous central nervous system (CNS) scedosporiosis. We continued treatment with antifungal therapy. He developed septic shock and expired on POD 55.

\section{Discussion}

Differential diagnoses for opportunistic pathogens causing pneumonia related to near-drowning events include several key pathogenic bacteria and fungi. Gram negative bacteria are most often the causative agents in near-drowning cases [13]. Aeromonas spp. have been described most often in near-drowning pneumonia cases. Aeromonas spp. naturally thrive in fresh and brackish waters and have been isolated 
TABLE 1: Culture results.

\begin{tabular}{|c|c|c|c|}
\hline Date & Culture site & Source & Result \\
\hline POD 28 & Abdominal fluid & Surgical specimen & $\begin{array}{l}\text { C. tropicalis } \\
\text { E. faecalis } \\
\text { E. coli } \\
\text { M. morganii }\end{array}$ \\
\hline POD 28 & Biloma fluid & Surgical specimen & $\begin{array}{l}\text { E. faecium } \\
\text { E. faecalis } \\
\text { S. apiospermum } \\
\text { C. tropicalis }\end{array}$ \\
\hline POD 28 & Perihepatic fluid & Surgical specimen & $\begin{array}{l}\text { S. apiospermum } \\
\text { E. faecium } \\
\text { C. tropicalis }\end{array}$ \\
\hline POD 28 & Perinephric hematoma tissue & Surgical specimen & S. apiospermum \\
\hline POD 32 & Abdominal clot & Surgical specimen & S. apiospermum \\
\hline POD 32 & Intestinal serosal tissue & Surgical specimen & $\begin{array}{l}\text { S. apiospermum } \\
\text { E. faecium }\end{array}$ \\
\hline POD 50 & LUQ abdominal fluid & Surgical specimen & $\begin{array}{l}\text { C. glabrata } \\
\text { C. tropicalis }\end{array}$ \\
\hline POD 50 & Cerebrospinal fluid & Lumbar puncture & Negative \\
\hline
\end{tabular}

TABLE 2: Susceptibility testing of fungal isolates.

\begin{tabular}{|c|c|c|c|}
\hline Isolate & Resistant (MIC) & Intermediate (MIC) & Susceptible (MIC) \\
\hline Scedosporium apiospermum & $\begin{array}{c}\text { 5-Fluorocytosine }(>64), \\
\text { amphotericin } B(>16), \\
\text { caspofungin }(>8), \\
\text { micafungin }(>8), \\
\text { terbinafine }(>2)\end{array}$ & None & Voriconazole (1) \\
\hline Candida tropicalis & None & None & $\begin{array}{c}\text { Caspofungin }(\leq 0.25), \\
\text { fluconazole }(\leq 1), \\
\text { voriconazole }(\leq 0.12)\end{array}$ \\
\hline Candida glabrata & None & None & $\begin{array}{c}\text { Caspofungin }(2), \\
\text { fluconazole }(\leq 1), \\
\text { voriconazole }(\leq 0.12)\end{array}$ \\
\hline
\end{tabular}

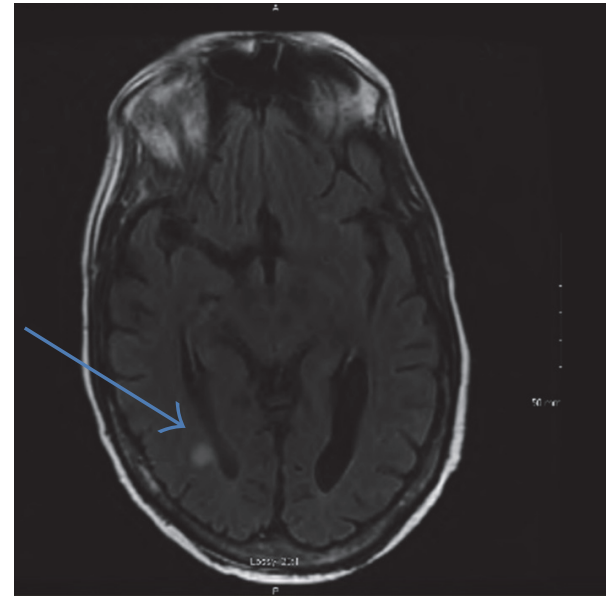

FIGURE 2: MRI of the brain. Multiple ring-enhancing lesions with associated diffusion restriction and T2/FLAIR hyperintensity are present throughout the supratentorial white matter.

in humans in wound and gastrointestinal infections after exposure to contaminated water. Other potential bacterial pathogens include Pseudomonas aeruginosa, Legionella spp., Klebsiella spp., and other Enterobacteriaceae [13]. Scedosporium spp. are the most common cause of invasive fungal infection, including pneumonia, CNS disease, and dissemination following near-drowning.

We identified 60 published cases of scedosporiosis after solid organ transplantation between the year 2000 and the present. Few were cases of scedosporiosis after solitary liver transplantation (5/60); most were reported following solitary lung (18/60) or kidney (18/60) transplantation. Table 3 $[2,12,14-42]$ provides a summary of the comprehensive literature review performed. S. apiospermum was isolated in the majority of cases, though S. prolificans and S. aurantiacum were also isolated. In four cases, both $S$. apiospermum and $S$. prolificans were identified in the same patient. In patients who had infections with a single isolate of Scedosporium spp., the observed mortality rates of S. apiospermum, S. prolificans, and S. aurantiacum were $54.5 \%(24 / 44), 70 \%$ (7/10), and $100 \%(3 / 3)$, respectively (excluding four cases with combined infections). Observed mortality of all Scedosporium spp. infections was 59\% (36/61) including our patient case.

Kim et al. reported three fatal and two nonfatal cases of scedosporiosis following solid organ transplantation from 
TABLE 3: Review of solid organ transplant-associated Scedosporium infection.

\begin{tabular}{|c|c|c|c|c|c|c|c|}
\hline \multirow{2}{*}{ Ref \# } & \multirow{2}{*}{ Year } & \multicolumn{2}{|c|}{ Recipient information } & \multirow{2}{*}{$\begin{array}{l}\text { Recipient } \\
\operatorname{organ}(\mathrm{s})\end{array}$} & \multirow{2}{*}{ Species of Scedosporium } & \multirow{2}{*}{ Treatment approach } & \multirow{2}{*}{ Outcome } \\
\hline & & Age (years) & Gender & & & & \\
\hline$[14]$ & 2000 & 67 & Male & Heart & apiospermum & Voriconazole & Deceased \\
\hline \multirow{7}{*}[15]{} & \multirow{7}{*}{2001} & 42 & Female & Heart/lung & apiospermum & Fluconazole, itraconazole & Deceased \\
\hline & & 22 & Female & Heart/lung & prolificans + apiospermum & Fluconazole, itraconazole & Deceased \\
\hline & & 42 & Male & Heart/lung & prolificans + apiospermum & Fluconazole, itraconazole & Alive \\
\hline & & 49 & Male & Lung & prolificans + apiospermum & Fluconazole, itraconazole & Deceased \\
\hline & & 39 & Male & Lung & prolificans + apiospermum & Fluconazole, itraconazole & Alive \\
\hline & & 52 & Female & Lung & apiospermum & Fluconazole, itraconazole & Alive \\
\hline & & 38 & Female & Heart/lung & apiospermum & Fluconazole, itraconazole & Deceased \\
\hline \multirow{7}{*}[16]{} & \multirow{7}{*}{2002} & 58 & Female & Liver & apiospermum & Itraconazole, miconazole & Alive \\
\hline & & 37 & Male & Lung & apiospermum & Itraconazole & Deceased \\
\hline & & 30 & Male & Lung & apiospermum & Amphotericin B, miconazole & Deceased \\
\hline & & 37 & Female & Heart/lung & apiospermum & Miconazole & Deceased \\
\hline & & 39 & Male & Liver & apiospermum & 5-Flucytosine, amphotericin B & Deceased \\
\hline & & 67 & Male & Heart & apiospermum & Itraconazole, voriconazole & Deceased \\
\hline & & 36 & Male & Kidney & apiospermum & Itraconazole, miconazole & Deceased \\
\hline [17] & 2002 & 49 & Male & Kidney & apiospermum & Voriconazole & Deceased \\
\hline \multirow{2}{*}[18]{} & \multirow{2}{*}{2002} & 62 & Female & Kidney & apiospermum & None & Deceased \\
\hline & & 58 & Male & Kidney & apiospermum & Itraconazole, voriconazole & Alive \\
\hline$[19]$ & 2002 & 64 & Female & Lung & apiospermum & Amphotericin B, itraconazole & Deceased \\
\hline$[20]$ & 2002 & 71 & Male & Heart & apiospermum & Itraconazole & Alive \\
\hline \multirow{2}{*}[21]{} & \multirow{2}{*}{2003} & 24 & Male & Lung & apiospermum & Voriconazole & Alive \\
\hline & & 59 & Male & Kidney & apiospermum & Voriconazole & Alive \\
\hline$[22]$ & 2004 & 50 & Male & Kidney & apiospermum & Voriconazole & Alive \\
\hline$[23]$ & 2004 & 58 & Male & Kidney & apiospermum & $\begin{array}{l}\text { Amphotericin B, fluconazole, } \\
\text { itraconazole, miconazole }\end{array}$ & Alive \\
\hline$[24]$ & 2004 & 56 & Female & Lung & prolificans & Voriconazole & Deceased \\
\hline \multirow{13}{*}[25]{} & \multirow{13}{*}{2005} & 55 & Male & Small bowel & prolificans & Amphotericin B & Deceased \\
\hline & & 40 & Male & Kidney/pancreas & prolificans & Voriconazole & Alive \\
\hline & & 67 & Male & Kidney & apiospermum & Amphotericin B & Alive \\
\hline & & 51 & Female & Small bowel & prolificans & $\begin{array}{c}\text { Amphotericin B, Voriconazole, } \\
\text { caspofungin }\end{array}$ & Deceased \\
\hline & & 67 & Male & Heart & apiospermum & Voriconazole & Deceased \\
\hline & & 17 & Male & Liver & prolificans & Voriconazole & Deceased \\
\hline & & 64 & Male & Liver & apiospermum & None & Deceased \\
\hline & & 45 & Male & Heart & apiospermum & Itraconazole & Deceased \\
\hline & & 56 & Male & Liver & apiospermum & Voriconazole & Deceased \\
\hline & & 44 & Female & Heart & prolificans & Amphotericin B & Deceased \\
\hline & & 68 & Male & Kidney & prolificans & Voriconazole & Alive \\
\hline & & 52 & Male & Small bowel & apiospermum & $\begin{array}{c}\text { Amphotericin B, Voriconazole, } \\
\text { caspofungin }\end{array}$ & Alive \\
\hline & & 62 & Male & Kidney/pancreas & apiospermum & Voriconazole & Alive \\
\hline$[26]$ & 2005 & 26 & Female & Lung & apiospermum & Miconazole, voriconazole & Deceased \\
\hline [27] & 2006 & 58 & Male & Kidney & apiospermum & Miconazole, voriconazole & Alive \\
\hline \multirow[b]{2}{*}[28]{} & \multirow[b]{2}{*}{2006} & 57 & Male & Lung & apiospermum & Terbinafine, voriconazole & Alive \\
\hline & & 63 & Male & Lung & apiospermum & $\begin{array}{l}\text { Liposomal amphotericin B, } \\
\text { terbinafine, voriconazole }\end{array}$ & Alive \\
\hline
\end{tabular}


TABle 3: Continued.

\begin{tabular}{|c|c|c|c|c|c|c|c|}
\hline \multirow{2}{*}{ Ref \# } & \multirow{2}{*}{ Year } & \multicolumn{2}{|c|}{ Recipient information } & \multirow{2}{*}{$\begin{array}{l}\text { Recipient } \\
\operatorname{organ}(s)\end{array}$} & \multirow{2}{*}{ Species of Scedosporium } & \multirow{2}{*}{ Treatment approach } & \multirow{2}{*}{ Outcome } \\
\hline & & Age (years) & Gender & & & & \\
\hline [29] & 2007 & 59 & Female & Kidney & apiospermum & Voriconazole & Alive \\
\hline$[30]$ & 2007 & 43 & Male & Lung & apiospermum & $\begin{array}{l}\text { Caspofungin, itraconazole, } \\
\text { liposomal amphotericin B }\end{array}$ & Deceased \\
\hline$[31]$ & 2008 & 70 & Male & Kidney & prolificans & Terbinafine, voriconazole & Alive \\
\hline$[32]$ & 2009 & 65 & Female & Kidney & apiospermum & Voriconazole & Alive \\
\hline$[33]$ & 2010 & 37 & Female & Lung & apiospermum & $\begin{array}{c}\text { Caspofungin, terbinafine, } \\
\text { voriconazole }\end{array}$ & Deceased \\
\hline$[34]$ & 2011 & 16 & Female & Lung & apiospermum & Voriconazole & Alive \\
\hline [35] & 2012 & 35 & Male & Lung/liver & apiospermum & Caspofungin, voriconazole & Deceased \\
\hline$[36]$ & 2012 & 37 & Female & Lung & apiospermum & $\begin{array}{c}\text { Aerosolized amphotericin } \mathrm{B}, \\
\text { caspofungin, itraconazole, } \\
\text { voriconazole }\end{array}$ & Deceased \\
\hline$[37]$ & 2013 & 17 & Female & Lung & apiospermum & $\begin{array}{c}\text { Caspofungin, posaconazole, } \\
\text { voriconazole }\end{array}$ & Alive \\
\hline$[38]$ & 2013 & 70 & Female & Lung & prolificans & $\begin{array}{c}\text { Caspofungin, terbinafine, } \\
\text { voriconazole }\end{array}$ & Deceased \\
\hline [39] & 2014 & 50 & Female & Kidney & apiospermum & Voriconazole & Alive \\
\hline$[40]$ & 2014 & 35 & Male & Kidney & prolificans & $\begin{array}{c}\text { Itraconazole, liposomal } \\
\text { amphotericin } \mathrm{B} \text {, micafungin, } \\
\text { voriconazole }\end{array}$ & Deceased \\
\hline$[41]$ & 2015 & 70 & Male & Heart & apiospermum & Posaconazole, terbinafine & Deceased \\
\hline \multirow{3}{*}[12]{} & \multirow{3}{*}{2015} & 19 & Male & Heart & aurantiacum & Amphotericin B prophylaxis & Deceased \\
\hline & & 56 & Male & Kidney & aurantiacum & $\begin{array}{c}\text { Itraconazole, liposomal } \\
\text { amphotericin B }\end{array}$ & Deceased \\
\hline & & 57 & Female & Kidney & aurantiacum & Caspofungin, voriconazole & Deceased \\
\hline [2] & 2015 & 40 & Male & Kidney & apiospermum & Voriconazole & Deceased \\
\hline [42] & 2015 & 18 & Female & Lung & apiospermum & Terbinafine, voriconazole & Alive \\
\hline
\end{tabular}

the same donor who was victim to a near-drowning accident [12]. Additionally, they reviewed national Korean data on transplants and found that, among 2600 deceased-donor transplants over thirteen years, $27(1 \%)$ of donors were victims of drowning. We accessed data from the United States Organ Procurement and Transplantation Network and found a similar rate: in 2015, 102/7586 (approximately 1.3\%) of solid organ donors died of near-drowning events [43]. While this is a low percentage of all donors, the significance of our case is enhanced by the $58.3 \%$ mortality rate of infections involving Scedosporium spp. after solid organ transplantation.

At our center, liver transplant recipients are given antifungal prophylaxis based on their risk level. We stratify higher risk patients as those with MELD scores greater than 35 , renal failure, requiring hemodialysis or $\mathrm{CVVH}$ prior to transplantation, recurrent spontaneous bacterial peritonitis, or preoperative prealbumin less than 10. High risk liver transplant recipients receive micafungin intravenously unless resistant Candida glabrata, Aspergillus spp., or Cryptococcus spp. are suspected; in such cases, amphotericin B lipid complex or voriconazole would be used. Our patient was classified as high risk and given micafungin prophylaxis.

All cases of suspected donor-derived infections should be reported to the DTAC. Communications with the CDC,
DTAC, and the centers treating the recipients of the other organs provided by this donor revealed the recipient of the heart was receiving voriconazole prophylaxis, while the recipients of the other kidney and the pancreas were not. To the best of our knowledge, no other recipient of this donor's organs is infected with Scedosporium spp. The other centers were advised by the CDC to commence voriconazole prophylaxis for an undetermined duration. Expert opinion for the management of our patient's scedosporiosis was voriconazole targeting a trough of $2-4 \mathrm{mcg} / \mathrm{mL}$. Additionally, immunosuppression was to be limited or discontinued to improve infection clearance.

S. apiospermum is inherently resistant to amphotericin B, including the lipid formulations. Of the newer triazole antifungals, data on the in vitro activity of voriconazole is most robust, showing activity against $S$. apiospermum with MICs of 0.12 to $0.5 \mathrm{mcg} / \mathrm{mL}$ in clinical isolates [30]. Because of poor activity with single agents, various antifungal combinations have been examined for efficacy against S. apiospermum. Strong synergy was found in vitro between voriconazole and terbinafine against clinical isolates of Scedosporium spp. [30]. Combination of micafungin and voriconazole has demonstrated a synergistic effect against several fungi in vitro including Scedosporium spp. The synergistic mechanism may 
include reorganization of the cell wall allowing increased exposure of beta-glucan to the immune system [44].

In addition to antifungal agents, GM-CSF has been studied with some success $[44,45]$. While antifungal therapy remains crucial to recovery, the treatment of scedosporiosis infections depends on the function of the host's innate immune system, in particular, polymorphonuclear cells (PMNs). The mechanism of GM-CSF increases the antifungal action of PMNs in vitro [45].

Despite good allograft function, our patient did not survive disseminated infection with $S$. apiospermum after combined kidney and liver transplantation. The exact mode of transmission and acquisition of $S$. apiospermum in this patient remains uncertain. We suspect donor to recipient transmission as the donor was the victim of a near-drowning event and had chest radiographs suspicious for pneumonia; however, we cannot rule out recipient colonization or nosocomial infection after the transplant.

Infections caused by Scedosporium spp. following solid organ transplant, while not common, are often fatal for recipients. There are no standards of practice for prophylaxis for patients at risk for developing scedosporiosis, such as recipients of organs from nearly drowned donors. Considering our case and the scedosporiosis mortality rate over $50 \%$ and the low rate of nearly drowned donors, we recommend screening for Scedosporium spp. when donated organs originate from a near-drowning victim.

\section{Competing Interests}

The authors declare that there is no significant conflict of interests regarding the publication of this paper.

\section{References}

[1] L. S. Johnson, R. K. Shields, and C. J. Clancy, "Epidemiology, clinical manifestations, and outcomes of scedosporium infections among solid organ transplant recipients," Transplant Infectious Disease, vol. 16, no. 4, pp. 578-587, 2014.

[2] B. Bose, S. Sharma, P. Derrington, and D. Divi, "Scedosporium apiospermum peritonitis in a patient undergoing peritoneal dialysis," Nephrology, vol. 17, no. 5, pp. 521-522, 2012.

[3] A. Malini, N. S. Madhusudan, S. P. Sinhasan, and B. C. Harthimath, "A masquerading subcutaneous swelling caused by Scedosporium apiospermum: an emerging pathogen," Indian Journal of Pathology and Microbiology, vol. 58, no. 1, pp. 115-117, 2015.

[4] H. L. Wilson and K. J. Kennedy, "Scedosporium apiospermum brain abscesses in an immunocompetent man with silicosis," Medical Mycology Case Reports, vol. 2, no. 1, pp. 75-78, 2013.

[5] J. M. Schaenman, D. B. DiGiulio, L. F. Mirels et al., "Scedosporium apiospermum soft tissue infection successfully treated with voriconazole: potential pitfalls in the transition from intravenous to oral therapy," Journal of Clinical Microbiology, vol. 43, no. 2, pp. 973-977, 2005.

[6] T. J. Walsh, A. Groll, J. Hiemenz, R. Fleming, E. Roilides, and E. Anaissie, "Infections due to emerging and uncommon medically important fungal pathogens," Clinical Microbiology and Infection, vol. 10, supplement 1, pp. 48-66, 2004.
[7] K. J. Cortez, E. Roilides, F. Quiroz-Telles et al., "Infections caused by Scedosporium spp," Clinical Microbiology Reviews, vol. 21, no. 1, pp. 157-197, 2008.

[8] P. T. Ender and M. J. Dolan, "Pneumonia associated with neardrowning," Clinical Infectious Diseases, vol. 25, no. 4, pp. 896907, 1997.

[9] A. Katragkou, J. Dotis, M. Kotsiou, M. Tamiolaki, and E. Roilides, "Scedosporium apiospermum infection after neardrowning," Mycoses, vol. 50, no. 5, pp. 412-421, 2007.

[10] P. A. Kowacs, C. E. Soares Silvado, S. Monteiro de Almeida et al., "Infection of the CNS by Scedosporium apiospermum after near drowning. Report of a fatal case and analysis of its confounding factors," Journal of Clinical Pathology, vol. 57, no. 2, pp. 205-207, 2004.

[11] M. S. Patel, A. J. Wright, R. Kohn, J. F. Markmann, C. N. Kotton, and P. A. Vagefi, "Successful long-term management of invasive cerebral fungal infection following liver transplantation," Mycoses, vol. 58, no. 3, pp. 181-186, 2015.

[12] S.-H. Kim, Y. E. Ha, J.-C. Youn et al., "Fatal scedosporiosis in multiple solid organ allografts transmitted from a nearlydrowned donor," American Journal of Transplantation, vol. 15, no. 3, pp. 833-840, 2015.

[13] K. Hoetzenecker, H. J. Ankersmit, G. Lang et al., "Considerations on infectious complications using a drowned lung for transplantation," Transplant International, vol. 23, no. 7, pp. e32e34, 2010.

[14] S. Kusne, S. Ariyanayagam-Baksh, D. C. Strollo, and J. Abernethy, "Invasive Scedosporium apiospermum infection in a heart transplant recipient presenting with multiple skin nodules and a pulmonary consolidation," Transplant Infectious Disease, vol. 2, no. 4, pp. 194-196, 2000.

[15] M. Tamm, M. Malouf, and A. Glanville, "Pulmonary scedosporium infection following lung transplantation," Transplant Infectious Disease, vol. 3, no. 4, pp. 189-194, 2001.

[16] B. Castiglioni, D. A. Sutton, M. G. Rinaldi, J. Fung, and S. Kusne, "Pseudallescheria boydii (Anamorph scedosporium apiospermum) infection in solid organ transplant recipients in a tertiary medical center and review of the literature," Medicine, vol. 81, no. 5, pp. 333-348, 2002.

[17] E. L. Campagnaro, K. J. Woodside, M. G. Early et al., "Disseminated Pseudallescheria boydii (Scedosporium apiospermum) infection in a renal transplant patient," Transplant Infectious Disease, vol. 4, no. 4, pp. 207-211, 2002.

[18] M. Montejo, M. L. Muñiz, S. Zárraga et al., "Infection due to Scedosporium apiospermum in renal transplant recipients: a report of two cases and literature review of central nervous system and cutaneous infections by Pseudoallescheria boydii/Sc. apiospermum," Mycoses, vol. 45, no. 9-10, pp. 418-427, 2002.

[19] R. Raj and A. E. Frost, "Scedosporium apiospermum fungemia in a lung transplant recipient," Chest, vol. 121, no. 5, pp. 17141716, 2002.

[20] T. R. Talbot, J. Hatcher, S. F. Davis, R. N. Pierson III, R. Barton, and S. Dummer, "Scedosporium apiospermum pneumonia and sternal wound infection in a heart transplant recipient," Transplantation, vol. 74, no. 11, pp. 1645-1647, 2002.

[21] J. Fortún, P. Martín-Dávila, M. A. Sánchez et al., "Voriconazole in the treatment of invasive mold infections in transplant recipients," European Journal of Clinical Microbiology and Infectious Diseases, vol. 22, no. 7, pp. 408-413, 2003.

[22] J. Ahmed, D. M. Ditmars, T. Sheppard, R. Del Busto, K. K. Venkat, and R. Parasuraman, "Recurrence of Scedosporium 
apiospermum infection following renal re-transplantation," American Journal of Transplantation, vol. 4, no. 10, pp. 17201724, 2004.

[23] D. Reimann, E. Büssemaker, and P. Gross, "Successful treatment due to vacuum seal technique of a severe Scedosporium apiospermum skin infection in a renal transplant recipient," Nephrology Dialysis Transplantation, vol. 19, no. 1, pp. 245-248, 2004.

[24] M. R. Vagefi, E. T. Kim, R. G. Alvarado, J. L. Duncan, E. L. Howes, and J. B. Crawford, "Bilateral endogenous Scedosporium prolificans endophthalmitis after lung transplantation," American Journal of Ophthalmology, vol. 139, no. 2, pp. 370-373, 2005.

[25] S. Husain, P. Muñoz, G. Forrest et al., "Infections due to Scedosporium apiospermum and Scedosporium prolificans in transplant recipients: clinical characteristics and impact of antifungal agent therapy on outcome," Clinical Infectious Diseases, vol. 40, no. 1, pp. 89-99, 2005.

[26] F. Symoens, C. Knoop, M. Schrooyen et al., "Disseminated Scedosporium apiospermum infection in a cystic fibrosis patient after double-lung transplantation," Journal of Heart and Lung Transplantation, vol. 25, no. 5, pp. 603-607, 2006.

[27] C. Farina, E. Gotti, F. Suter, and A. Goglio, "Scedosporium apiospermum soft-tissue infection: a case report and review of kidney transplant literature," Transplantation Proceedings, vol. 38, no. 5, pp. 1333-1335, 2006.

[28] M. Musk, D. Chambers, W. Chin, R. Murray, and E. Gabbay, "Successful treatment of disseminated Scedosporium infection in 2 lung transplant recipients: review of the literature and recommendations for management," Journal of Heart and Lung Transplantation, vol. 25, no. 10, pp. 1268-1272, 2006.

[29] P. G. Rogasi, M. Zanazzi, J. Nocentini et al., "Disseminated Scedosporium apiospermum infection in renal transplant recipient: long-term successful treatment with voriconazole: a case report," Transplantation Proceedings, vol. 39, no. 6, pp. 20332035, 2007.

[30] H. Sahi, R. K. Avery, O. A. Minai et al., "Scedosporium apiospermum (Pseudoallescheria boydii) Infection in lung transplant recipients," Journal of Heart and Lung Transplantation, vol. 26, no. 4, pp. 350-356, 2007.

[31] J. Y. Z. Li, T. Y. Yong, D. I. Grove, and P. T. H. Coates, "Successful control of Scedosporium prolificans septic arthritis and probable osteomyelitis without radical surgery in a long-term renal transplant recipient," Transplant Infectious Disease, vol. 10, no. 1, pp. 63-65, 2008.

[32] K. Ezzedine, K. M. Wissing, F. Jacobs, H. Rodriguez, D. Malvy, and T. Simonart, "Recurrent Scedosporium apiospermum skin infection in a renal transplant recipient," Journal of the European Academy of Dermatology and Venereology, vol. 23, no. 1, pp. 9596, 2009.

[33] F. Morio, D. Horeau-Langlard, F. Gay-Andrieu et al., "Disseminated Scedosporium/Pseudallescheria infection after doublelung transplantation in patients with cystic fibrosis," Journal of Clinical Microbiology, vol. 48, no. 5, pp. 1978-1982, 2010.

[34] B. Luijk, M. B. Ekkelenkamp, P. A. De Jong et al., "Effective prolonged therapy with voriconazole in a lung transplant recipient with spondylodiscitis induced by Scedosporium apiospermum," Case Reports in Infectious Diseases, vol. 2011, Article ID 460313, 4 pages, 2011.

[35] S. Hirschi, V. Letscher-Bru, J. Pottecher et al., "Disseminated Trichosporon mycotoxinivorans, Aspergillus fumigatus, and Scedosporium apiospermum coinfection after lung and liver transplantation in a cystic fibrosis patient," Journal of Clinical Microbiology, vol. 50, no. 12, pp. 4168-4170, 2012.

[36] F. Miraldi, M. Anile, F. Ruberto et al., "Scedosporium apiospermum atrial mycetomas after lung transplantation for cystic fibrosis," Transplant Infectious Disease, vol. 14, no. 2, pp. 188-191, 2012.

[37] C. Hartmann, C. Müller, H. Weißbrodt et al., "Successful prevention of scedosporiosis after lung transplantation in a cystic fibrosis patient by combined local and systemic triazole therapy," Medical Mycology Case Reports, vol. 2, no. 1, pp. 116118, 2013.

[38] D. M. Sayah, B. S. Schwartz, J. Kukreja, J. P. Singer, J. A. Golden, and L. E. Leard, "Scedosporium prolificans pericarditis and mycotic aortic aneurysm in a lung transplant recipient receiving voriconazole prophylaxis," Transplant Infectious Disease, vol. 15, no. 2, pp. E70-E74, 2013.

[39] M. Rathi, S. Gundlapalli, R. Ramachandran et al., "A rare case of cytomegalovirus, scedosporium apiospermum and mycobacterium tuberculosis in a renal transplant recipient," BMC Infectious Diseases, vol. 14, article 259, 2014.

[40] K. Uno, K. Kasahara, S. Kutsuna et al., "Infective endocarditis and meningitis due to Scedosporium prolificans in a renal transplant recipient," Journal of Infection and Chemotherapy, vol. 20, no. 2, pp. 131-133, 2014.

[41] M. E. Clement, E. K. Maziarz, J. N. Schroder, C. B. Patel, and J. R. Perfect, "Scedosporium apiosermum infection of the 'Native' valve: fungal endocarditis in an orthotopic heart transplant recipient," Medical Mycology Case Reports, vol. 9, pp. 34-36, 2015.

[42] A. Sharma and D. Singh, "Scedosporium apiospermum causing brain abscess in a renal allograft recipient," Saudi Journal of Kidney Diseases and Transplantation, vol. 26, no. 6, pp. 12531256, 2015.

[43] Deceased Donors Recovered in the U.S. by Mechanism of Death: Transplant Data 1988-2015, Department of Health and Human Services, Health Resources and Services Administration, Healthcare Systems Bureau, Division of Transplantation, Rockville, MD; United Network for Organ Sharing, Richmond, VA; University Renal Research and Education Association, Ann Arbor, MI.

[44] C. Goldman, M. J. Akiyama, J. Torres, E. Louie, and S. A. Meehan, "Scedosporium apiospermum infections and the role of combination antifungal therapy and GM-CSF: a case report and review of the literature," Medical Mycology Case Reports, vol. 11, pp. 40-43, 2016.

[45] M. J. Abzug and T. J. Walsh, "Interferon- $\gamma$ and colony-stimulating factors as adjuvant therapy for refractory fungal infections in children," Pediatric Infectious Disease Journal, vol. 23, no. 8, pp. 769-773, 2004. 


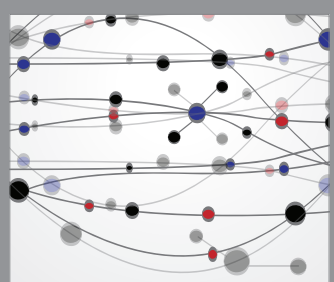

The Scientific World Journal
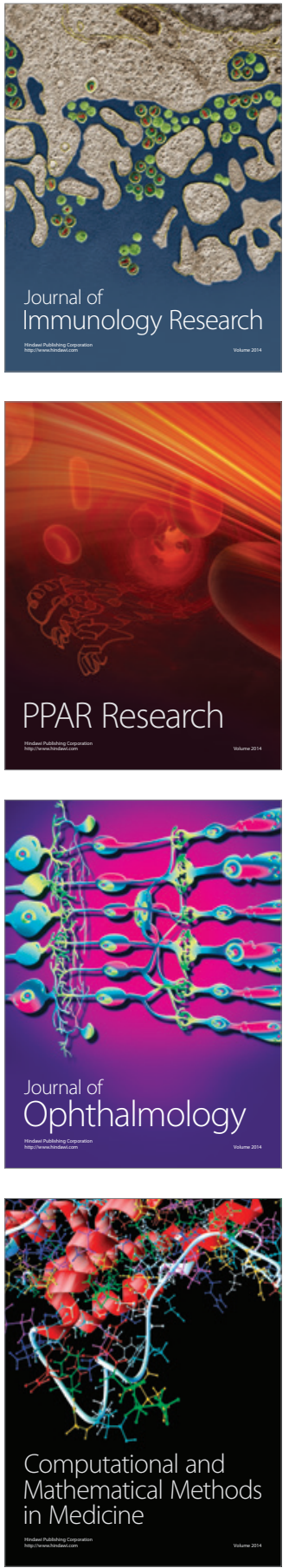

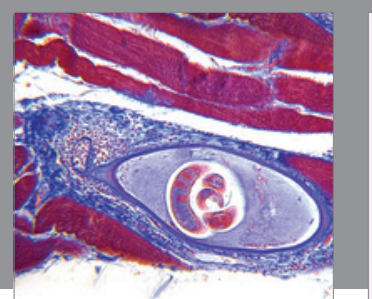

Gastroenterology Research and Practice

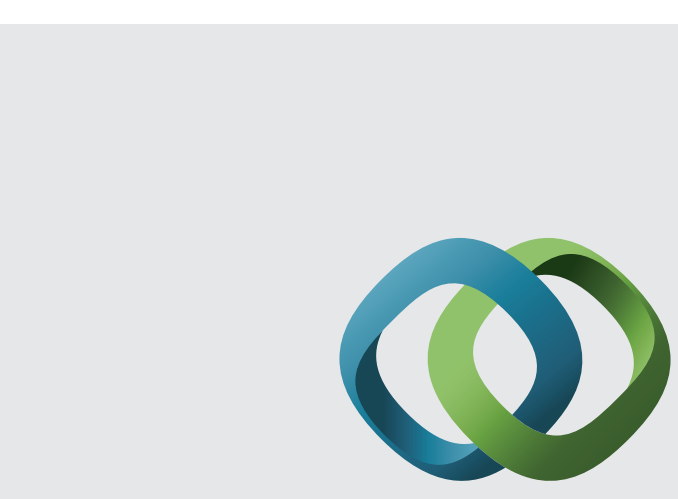

\section{Hindawi}

Submit your manuscripts at

http://www.hindawi.com
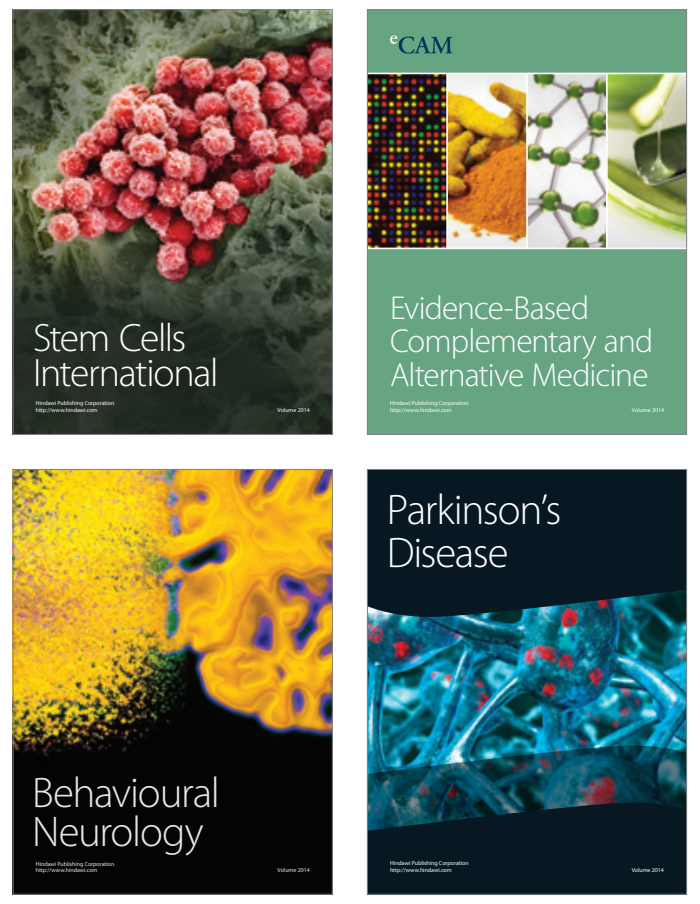
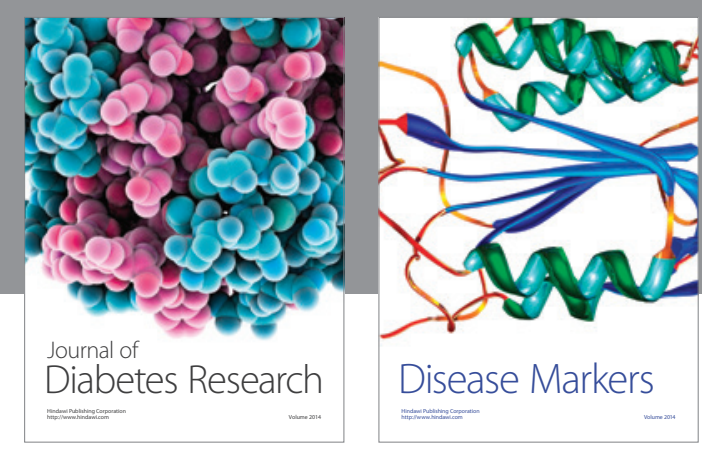

Disease Markers
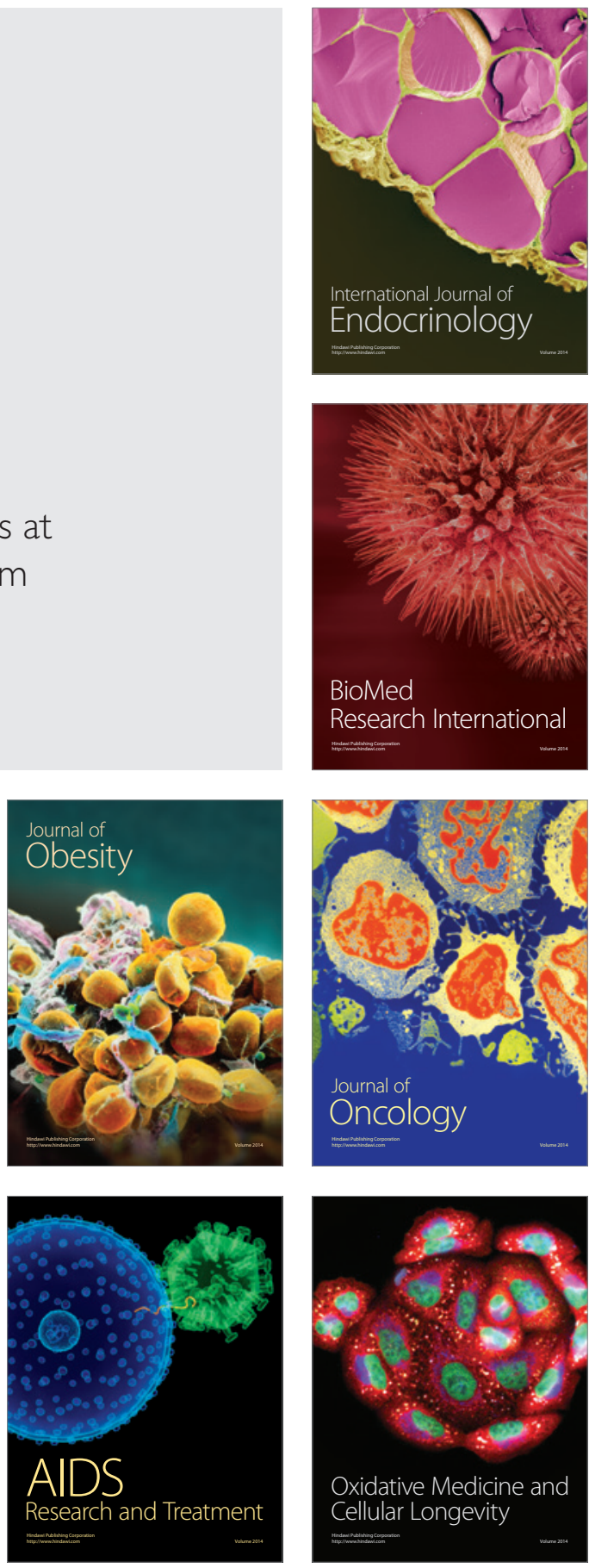